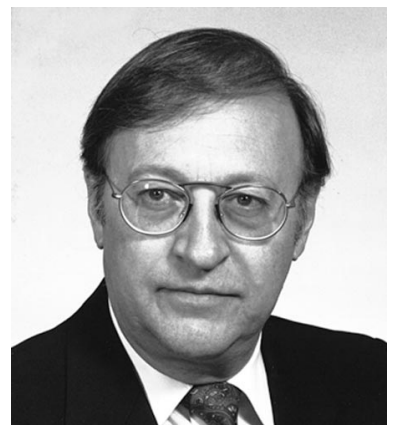

\section{Are we really afraid of basic optics?}

I think that it is probably the same thing everywhere, in North America at least. Most of those involved in training of highly qualified personnel very often receive requests for young specialists with excellent skills in optical system design. This is the most difficult request to respond to.

If we look at the way teaching is arranged in our universities, there are well-recognized fields in optics in the same way that there are well-organized areas in physics, chemistry, etc. Having well-organized areas in sciences means that all scientists converge toward the most popular and newly addressed aspects of problems. This is very nice. It attracts new heads in our field, but also permits elimination of heads from certain areas they may have chosen to enter before being exposed to some kind of publicity. Very often, supposedly well-thinking professors will say very discouraging remarks about a colleague who is doing a good and very professional job, but who is doing "old" physics or optics according to their standards.

So, most students choose areas that are frequently discussed in magazines, advertisements, etc.

This situation contributes to the lack of specialists in certain areas because the publicity completely forgets to mention the needs happening in these so-called "old", areas.

One of these areas is optical lens design. I cannot count how many times I have had to say "there is nobody available" in this area, or "there is nobody entering this area this year.' Our students want to study lasers, nonlinear optics, optical fibers, waveguides, multiplexers, etc. This is all very nice. But how many new developments rely on "old" optics? It is a pity that it is almost impossible to find one student who may even think of choosing this field, even though we are showing them the piles of requests we have on our desks.

These thoughts bring me back to our curriculum in which we all want to teach the latest discoveries and latest hot topics. We want students who will be very good in some topics without having to learn about basic instrumental optics.

My intention here is to bring this problem upfront to encourage brainstorming, which will permit us to find ways of avoiding this type of situation. Please remember us, when optics is considered as "old" science; it is not far away. Most of us did not laugh when our professors and colleagues were telling us that we were choosing old physics and there was nothing to do with that. It seems that in many places we are repeating these mistakes, and this time within our own discipline.

Hopefully, this little editorial may help some of us to start thinking about this problem and suggest ways by which we will be able to define objectives that will permit us to avoid the situation we have now. I used optical system design as an example, but there are others.

May I suggest that many of us should make use of the open panel for the conferences on Education and Training in Optics and Photonics to establish better communication and better exchange on this topic of defining curricula that will not pass over "old" areas of physics or optics.

Roger A. Lessard Editor 